\title{
Dust Modelling and Forecasting in the Barcelona Supercomputing Center: Activities and Developments
}

\author{
C Pérez ${ }^{1}$, J M Baldasano ${ }^{1,2}$, P Jiménez-Guerrero ${ }^{1}$, O Jorba $^{1}$, K Haustein $^{1}$, E \\ Cuevas $^{3}, S_{\text {Basart }}{ }^{1}$ and $S$ Nickovic ${ }^{4}$ \\ ${ }^{1}$ Earth Sciences Department. Barcelona Supercomputing Center. Barcelona, Spain. \\ ${ }^{2}$ Laboratory of Environmental Modeling. Universitat Politècnica de Catalunya. \\ Barcelona. Spain \\ ${ }^{3}$ Izaña Atmospheric Research Center. Agencia Estatal de Meteorología. Tenerife, \\ Spain. \\ ${ }^{4}$ Atmospheric Research and Environment Branch. World Meteorological \\ Organization. Geneva, Switzerland. \\ E-mail: carlos.perez@bsc.es
}

\begin{abstract}
The Barcelona Supercomputing Center (BSC) is the National Supercomputer Facility in Spain, hosting MareNostrum, one of the most powerful Supercomputers in Europe. The Earth Sciences Department of BSC operates daily regional dust and air quality forecasts and conducts intensive modelling research for short-term operational prediction. This contribution summarizes the latest developments and current activities in the field of sand and dust storm modelling and forecasting.
\end{abstract}

\section{Dust modelling and forecasting at BSC}

The Earth Sciences Department of BSC maintains dust forecast operations with the Dust REgional Atmospheric Model (DREAM) and conducts modelling research and developments for short-term prediction.

BSC-DREAM [1] predicts the atmospheric life cycle of the eroded desert dust and was developed as a pluggable component of the Eta/NCEP (National Centers for Environmental Prediction) model. BSC-DREAM solves the Euler-type partial differential non-linear equation for dust mass continuity and it is fully inserted as one of the governing prognosis equations in the atmospheric Eta/NCEP atmospheric model equations $[2,3,4,5,6,7,8,9,10]$.

BSC-DREAM simulates all the major processes of the atmospheric dust cycle. During model integration, calculation of the surface dust injection fluxes is made over the model grid points declared as deserts. Once injected into the air, dust aerosol is driven by the atmospheric model variables: by turbulent parameters in the early stage of the process when dust is lifted from the ground to the upper levels; by model winds in the later phases of the process when dust travels away from the sources; finally, by thermodynamic processes and rainfall of the atmospheric model and land cover features which provide wet and dry deposition of dust over the Earth surface.

One of the key components of the dust model is the treatment of the sourcing terms in the concentration continuity equation. Failure to adequately simulate/predict the production phase of the dust cycle leads to wrong representation of all other dust processes in the model. Therefore, special 
attention is made to properly parameterize dust production phase. Wind erosion of the soil in BSCDREAM parameterization scheme is controlled mainly by the following factors: type of soil, type of vegetation cover, soil moisture content, and surface atmospheric turbulence. In the model, grid points acting as desert dust sources are specified using arid and semiarid categories of the global USGS 1-km vegetation data set. Another data participating in dust production calculations is the FAO 4-km global soil texture data set from which particle size parameters are evaluated. The main general features of the model are listed below:

- Dust production scheme with introduced viscous sub-layer $[11,6]$.

- 8 particle size bin distribution.

- Soil wetness effects on dust production [12].

- Dry deposition [13] and below cloud scavenging.

- Horizontal and vertical advection, turbulent and lateral diffusion [6] represented as for other scalars in the Eta/NCEP model.

- Dust radiative feedbacks on meteorology [14].

Eight size transport bins between 0.1 and $10 \mu \mathrm{m}$ are considered. In this interval, the aerosol effects on solar radiation are the most significant. Within each transport bin, dust is assumed to have timeinvariant, sub-bin log-normal distribution [15] employing the transport mode with mass median diameter of $2.524 \mu \mathrm{m}$ [16] and geometric standard deviation 2.0 [17]. The analytic sub-bin distribution allows accurate prescription of physical and optical properties known to vary across the bin width.

Since there are not yet satisfactory three-dimensional dust concentration observations, the initial state of dust concentration in the model is defined by the 24-hour forecast from the previous-day model run. The model at the starting day is run using "cold start" conditions, i.e., the zeroconcentration initial state. The model needs about 2-3 days for spinning up and for establishing reliable dust concentration conditions.

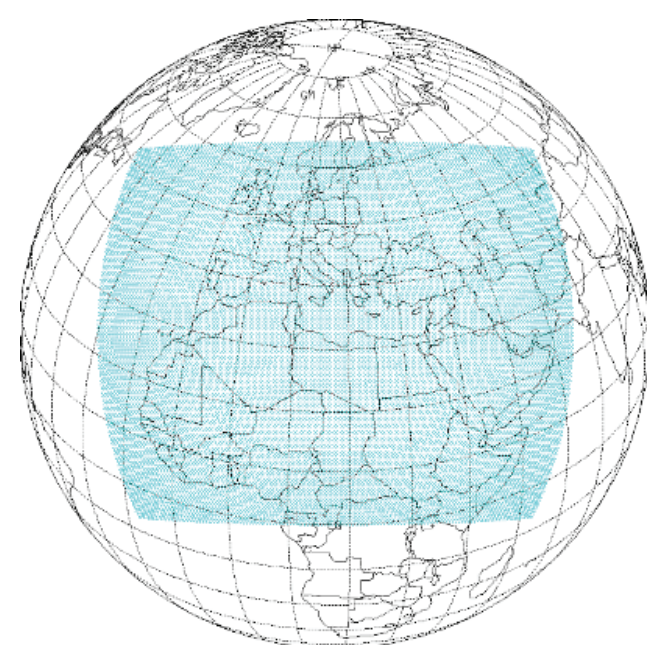

(a)

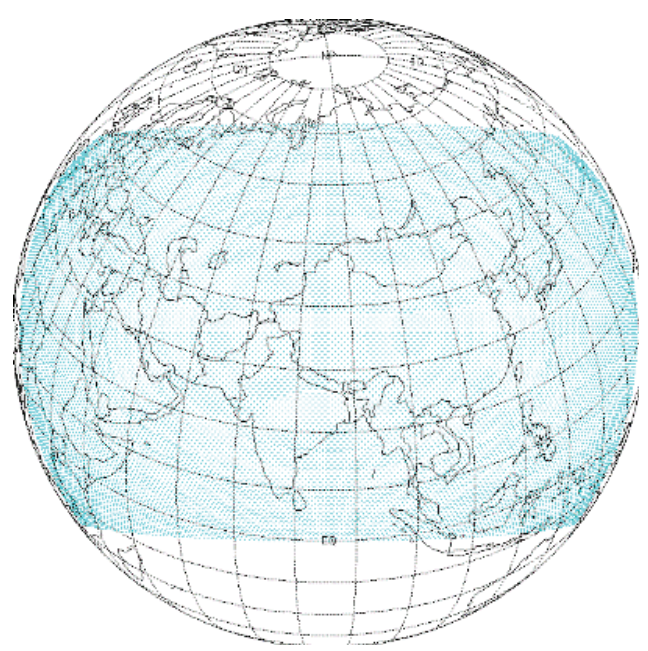

(b)

Figure 1. Northern Africa-Europe-Mediterranean-Middle East (a) and East-Asia (b) forecast domains of BSC-DREAM.

BSC-DREAM has been delivering operational dust $72 \mathrm{~h}$ forecasts over North Africa-EuropeMediterranean (which include North of Africa, the Mediterranean basin, Middle East and Europe) and Asia regions (figure 1) in the last years (http://www.bsc.es/projects/earthscience/DREAM). The operational resolution is $0.3^{\circ} \times 0.3^{\circ}$ and 24 layers up to $15 \mathrm{~km}$ in the vertical. 
The model qualitative and quantitative verification studies performed so far $[18,19,20]$ using data from observation networks such as the European Lidar Network EARLINET, the AERONET/PHOTONS sun photometer network, satellite and ground level PM levels (EMEP) outline the good skills of the model concerning both the horizontal and vertical extent of the dust plume in the geographic region of application. Additionally, the model has been validated and tested against measurements at source regions for SAMUM [21] and BODEX campaigns [22].

In order to improve of the dust forecast and implement new model versions and operational products, daily verification with near-real time observations (figure 2) is conducted in collaboration with the Spanish Meteorological State Agency (AEMET) and the Spanish National Research Council (CSIC). Currently, the verification system includes satellites (MODIS, MSG, OMI) and sun photometers (AERONET). Ongoing activities involve the inclusion of lidars, visibility reports and surface concentration measurements to the verification system.

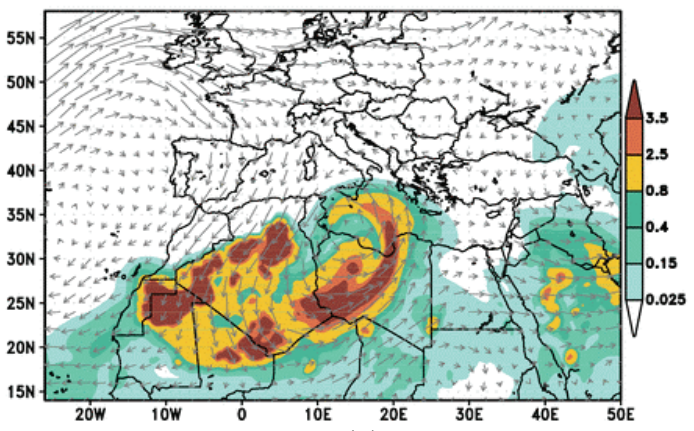

(a)

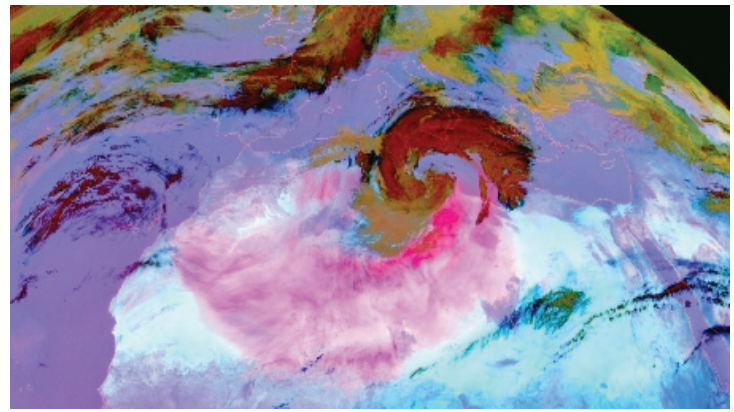

(b)

Figure 2. 24h BSC-DREAM forecast (a) and MSG dust RGB product (b) for 9th March 2007 at 12 UTC.

\section{Inclusion of Saharan dust in an integrated air quality forecasting system for Europe}

One of the most recent development activities related to dust modelling has focused on the implementation of a high-resolution air quality forecasting system for Europe and the Iberian Peninsula (CALIOPE Project supported by the Spanish Ministry of Environment) [23,24]. The dust contribution to PM levels is included through coupling of the WRF-ARW/HERMESEMEP/CMAQ/BSC-DREAM modelling system. The high resolution applied (12 km for Europe and 4 $\mathrm{km}$ for the Iberian Peninsula) helps providing a better understanding of the dynamics of atmospheric pollutants and allows for early communication to the dwellers in areas that exceed air quality thresholds. This service is available on the website http://www.bsc.es/caliope.

The complex atmospheric conditions in southern Europe involve the superposition of phenomena occurring at different scales that exert a high influence in the levels of particulate matter and its composition. Namely, the contribution of mineral aerosols is very high due to the existence of semiarid soils and specially the frequent occurrence of Saharan dust events in southern Europe. When considering only anthropogenic emissions, chemistry-transport model simulations recursively underestimate the PM10 and PM2.5 concentrations using the current knowledge about aerosol physics and chemistry. Therefore, the introduction of boundary conditions for Saharan dust is necessary in order to model correctly the PM mass over Europe. Dust peaks cannot be represented by introducing boundary conditions derived from a dust climatology due to the highly episodic nature of the events in the region (1-4 days average duration).

The necessity of coupling both aforementioned systems in an integrated framework was addressed by the study of year 2004 [20]. Figure 3 shows the average PM10 concentration in Europe with and without dust contribution. 


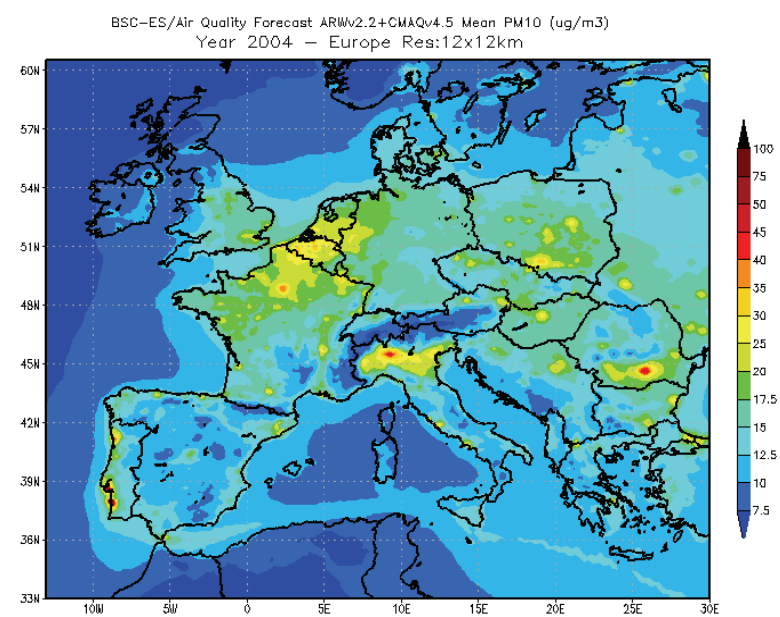

(a)

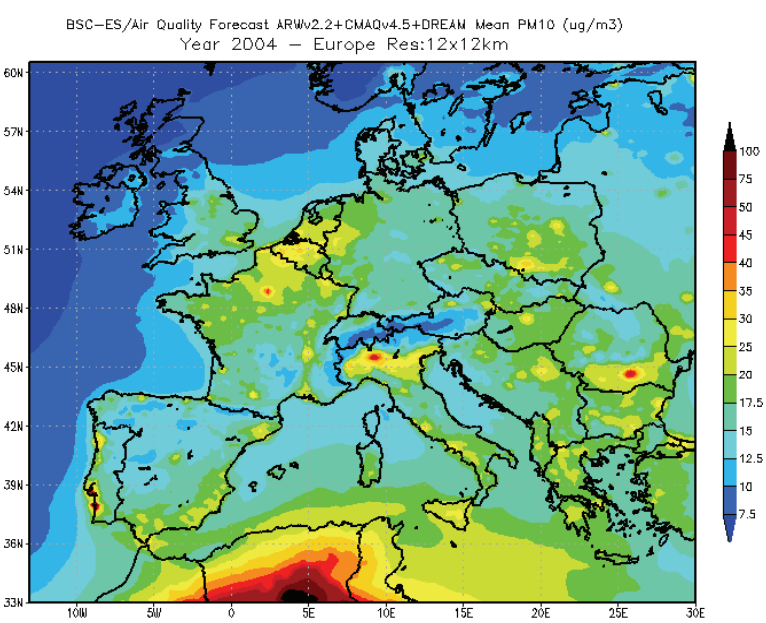

(b)

Figure 3. 2004 average PM10 Concentration $\left(\mu \mathrm{g} \mathrm{m}^{-3}\right)$ in Europe: anthropogenic contribution with CMAQ (a) and anthropogenic+dust levels with CMAQ+BSC-DREAM (b).

The performance of the model has been quantitatively evaluated with discrete and categorical (skill scores) statistics by a comparison of the first-layer simulations results of CMAQ+BSC-DREAM and the values measured in the European stations belonging to the EMEP network with available data for the year 2004 (26 stations for PM10 and 17 stations for PM2.5). The results indicate an improvement in the discrete statistics for particulate matter (the normalised bias improves from - $20 \%$ to $-9 \%$ and the normalised error from $36 \%$ to $30 \%$ when considering all the stations in Europe for an annual cycle) and skill-scores evaluation (accuracy, critical success index and probability of detection) of PM10 and PM2.5 concentrations when using CMAQ+BSC-DREAM compared to CMAQ-alone simulations. This improvement in the quality of the predictions becomes more important in those southern stations undergoing larger impacts of Saharan dust outbreaks (the normalised error improves from $40-60 \%$ to $30-40 \%$ for PM10 and from $30-40 \%$ to $25-30 \%$ for PM 2.5 concentrations). As an example, figure 4 shows the comparison at Viznar station in southern Spain.

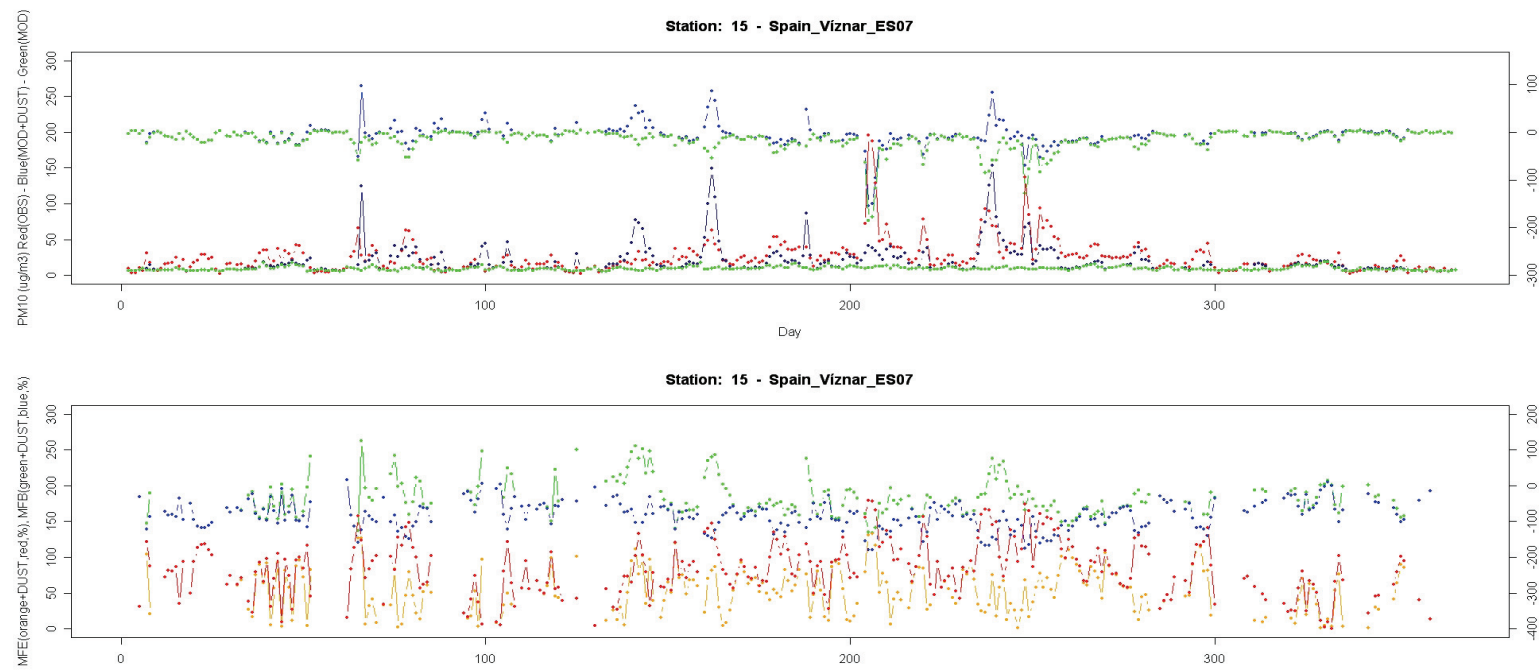

Figure 4. Comparison of modelled against observed PM10 concentrations in Víznar station (Spain): (up) Observations (red), CMAQ-alone (green), CMAQ+DREAM (blue) and their respective bias; (down) mean fractional bias (MFB) for CMAQ-alone (green), CMAQ+DREAM (blue) and mean fractional error (MFE) for CMAQ-alone (red) and CMAQ+DREAM (orange). 
The results of this work demonstrated that this first approach to the coupling of CMAQ anthropogenic outputs with BSC-DREAM natural dust forecasts in an operational way is necessary in order to improve the prediction of the particulate matter mass over southern Europe and to achieve the standards set in European Directives for modelling applications.

\section{Impact of mineral dust on numerical weather forecasts}

Several studies have suggested that the inclusion of mineral dust radiative effects could lead to a significant improvement in the radiative balance of numerical weather prediction models with subsequent improvements in the weather forecast itself. Recently, [25] related systematic short-term temperature forecast errors to the absence of dust radiative effects in models over the Saharan region. Also, [26] stated that the neglect of mineral dust in a NWP model is the most probable reason for the discrepancy in outgoing longwave radiation between the model and Meteosat-7 observations over northern Africa.

In this context, the radiative effects of mineral dust have been fully incorporated into BSCDREAM. Dust affects the radiative fluxes at the surface and the top of the atmosphere, and the temperature profiles at every time step of the model when the radiation module is processed. These changes influence the atmospheric dynamics, moisture physics and near-surface conditions. Furthermore, dust emission is modified by changes in friction velocity and turbulent exchange coefficients; dust turbulent mixing, transport and deposition are altered by changes in atmospheric stability, precipitation conditions and free-atmosphere winds.

The new scheme was tested for a major dust outbreak over the Mediterranean on April 2002 in order to assess the dust impacts on regional numerical weather forecasting [14]. It is shown that the newly developed atmosphere-dust feedback scheme increases the accuracy of both, atmospheric temperature and mean sea-level pressure forecasts (figure 5). Both low-level warm and upper-level cold temperature biases are considerably reduced when dust affects the atmosphere thermodynamics. The root mean square error of the mean sea level pressure over the whole domain was reduced by almost $20 \%$. The proposed model with integrated dust and atmospheric radiation represents a promising approach for further improvements in numerical weather prediction practice and radiative impact assessment over dust-affected areas.
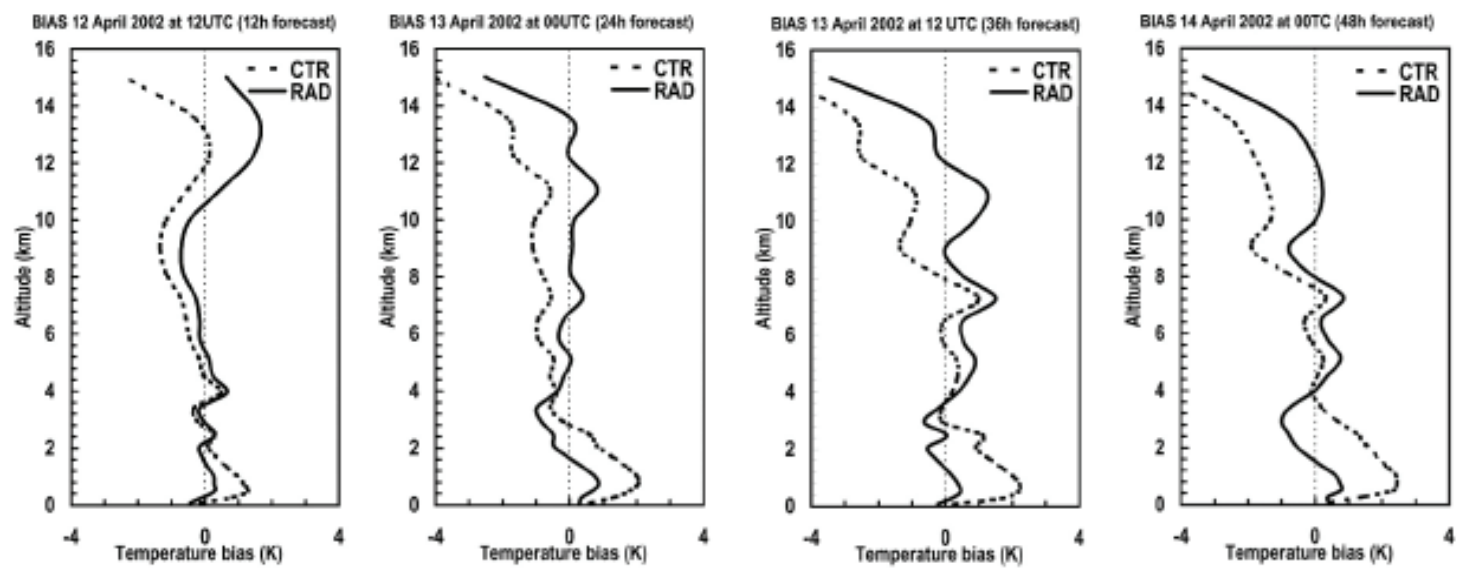

Figure 5. Atmospheric temperature bias of CTR and RAD over the main dust-affected area (comprised between latitude $30^{\circ} \mathrm{N}$ to $45^{\circ} \mathrm{N}$ and longitude 0 to $20^{\circ} \mathrm{E}$ ) for the $12,24,38$, and 48 hour forecasts of the 0000 UTC cycle on 12 April. Extracted from [14]. 


\section{Long term model integrations from 1958 to 2006: validation, analysis and applications}

Measurements since the 1960s have shown strong daily, seasonal and inter-annual variations of dust concentration over the Atlantic [27]. [28] used satellite data to outline the correlation between the NAO index and the dust distribution over North Africa and the Atlantic Ocean in the two last decades. [29] found similar results running a dust model for the period 1981-1996.

A 48-year model simulation was performed for the period $1958-2006$ at $0.3^{\circ} \times 0.3^{\circ}$ resolution (implemented in MareNostrum supercomputer) in order to analyze the monthly, seasonal and year-toyear variation of the atmospheric dust load, surface concentration, deposition and the frequency and duration of the events over the Mediterranean and the Eastern North Atlantic [30]. Meteorological fields were initialized every 24 hours and boundary conditions updated every 6 hours with the NCEP/NCAR I global reanalysis $\left(2.5^{\circ} \times 2.5^{\circ}\right.$ resolution). Satellite observations (figure $\left.6 \mathrm{a}\right)$ and in situ measurements of concentrations at the Izaña station (Canary Islands) for the period 1987-1999 and in southern Europe were used for model validation.

We explored links of the simulated dust parameters to the variability of the large-scale circulation in winter covering decades with mostly positive (1981-2006) and mostly negative (1958-1980) NAO index (figure $6 \mathrm{~b}$ ). The model fairly well represents the interannual winter variability over the Atlantic (figure 6a). In agreement with previous studies we find high NAO dust correlations over the Atlantic Ocean and the southern Sahara/Sahel region within the period 1981-2006 (figure 6c). However, the correlation is significantly decreased when NAO index is mostly negative (1958-1980) (figure 6d).

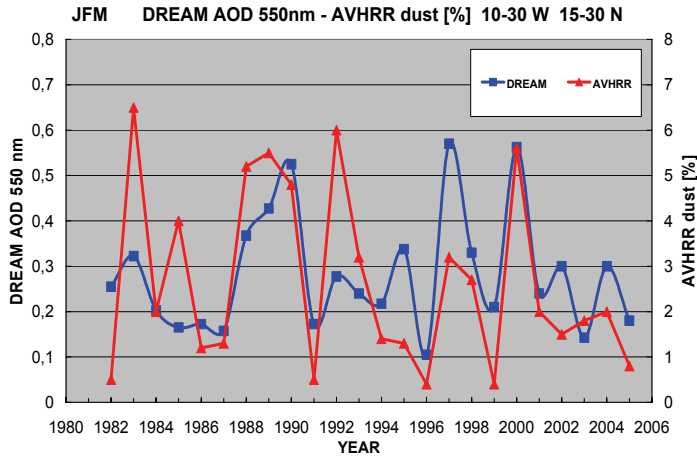

(a)

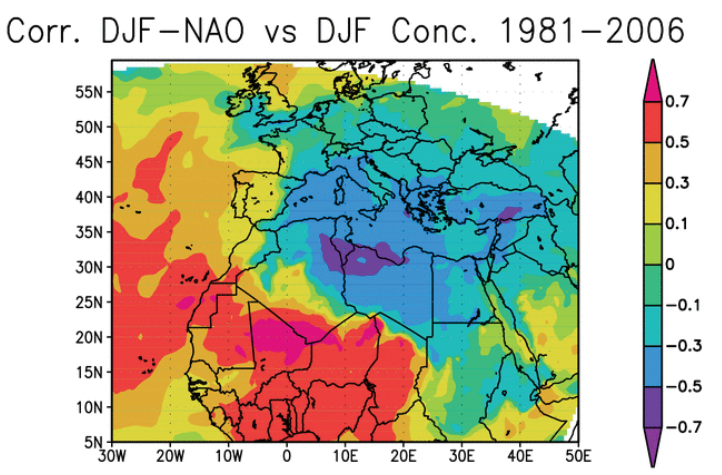

(c)

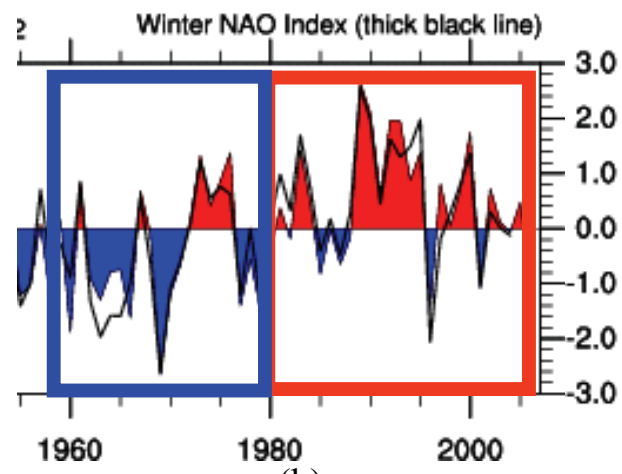

(b)

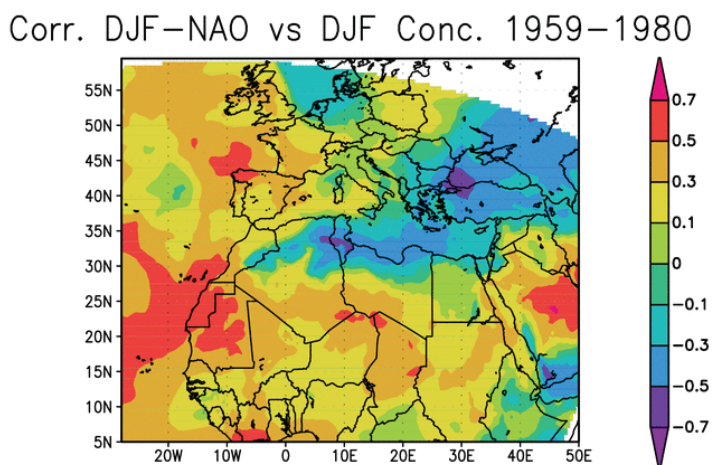

(d)

Figure 6. (a) Comparison of winter (JFM) BSC-DREAM AOD with AVHRR dust qualitative product (Evan et al., 2006) over the Eastern Atlantic. Correlation coefficient is 0.62. (b) Winter NAO index. Blue square contains mostly negative phases in the period 1958-1980. Red square contains mostly positive phases in the period 1981-2006. Winter correlation between NAO index and modelled surface dust concentration in the periods 1981-2006 (c) and 1959-1880 (d). 


\section{Perspectives: an online mineral dust model within the global/regional NMMB}

While mineral dust distribution and effects are important on global scales, they strongly depend on dust emissions that are occurring on small spatial and temporal scales. Indeed, the accuracy of surface wind speed used in dust models is crucial. Due to the high-order power dependency on wind friction velocity and the threshold behaviour of dust emissions, small errors in surface wind speed lead to large dust emission errors. Most global dust models use prescribed wind fields provided by major meteorological centres (e.g., NCEP and ECMWF) and their spatial resolution is currently about $1^{\circ} \times 1^{\circ}$. Such wind speeds tend to be strongly underestimated over arid and semi-arid areas and do not account for mesoscale systems responsible for a significant fraction of dust emissions regionally and globally. Other significant uncertainties in dust emissions resulting from such approaches are related to the misrepresentation of high subgrid-scale spatial heterogeneity in soil and vegetation boundary conditions, mainly in semi-arid areas.

In order to significantly reduce these uncertainties, BSC is currently implementing a mineral dust model coupled on-line with the new global/regional NMMB (B-grid) atmospheric model using the ESMF framework under development in NOAA/NCEP/EMC [31]. The NMMB is an evolution of the operational WRF-NMME (E-grid) extending from meso to global scales, and including nonhydrostatic option and improved tracer advection. This model is planned to become the nextgeneration NCEP mesoscale model for operational weather forecasting in North America. Current implementation is based on the well established BSC-DREAM model. First successful global simulations show the potentials of such an approach and compare well to BSC-DREAM regionally (figure 7).

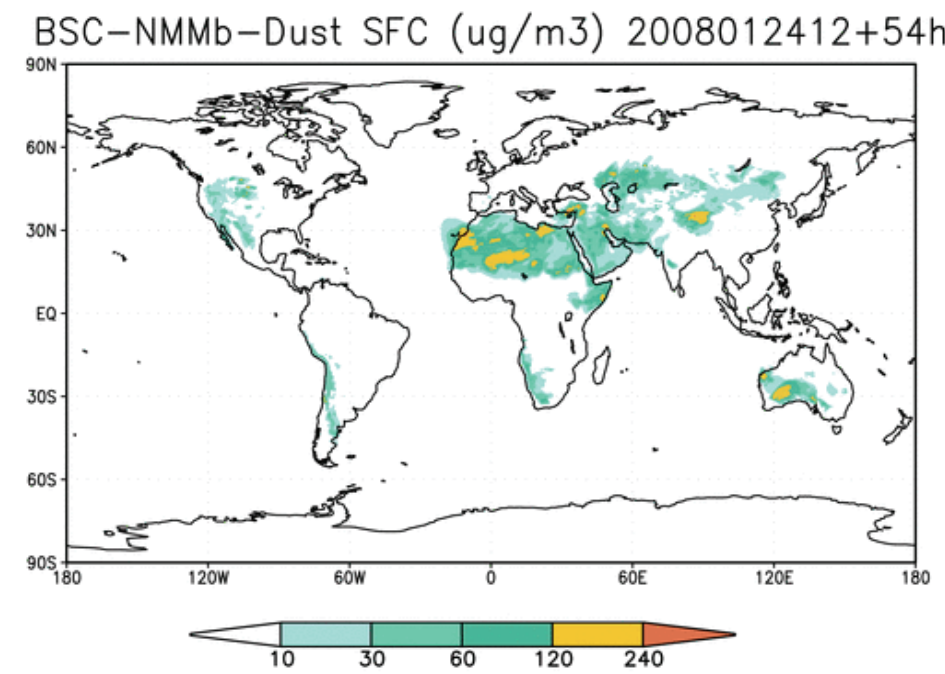

Figure 7. First tests with the NMMb/BSC-Dust model. Surface concentration in $\mu \mathrm{g} / \mathrm{m}^{3}$ of size bin $4[0.6-1 \mu \mathrm{m}]$ for the $54 \mathrm{~h}$ forecast of the 2008-01-24-12 cycle.

Ongoing developments include improvements in dust size distribution representation, sedimentation, dry deposition, wet scavenging and dust-radiation feedback, as well as the efficient implementation of the model on High Performance Supercomputers for global simulations and forecasts at high resolution.

\section{Acknowledgements}

This work was partly funded by the projects CICYT CGL2006-11879 and CGL2006-08903 of the Spanish Ministry of Education and Science and CALIOPE project 441/2006/3-12.1 of the Spanish Ministry of the Environment. 


\section{References}

[1] Nickovic et al., 2001 A model for prediction of desert dust cycle in the atmosphere. Journal of Geophysical Research, 106, D16, 18113-18129.

[2] Janjic, Z. I., 1977 Pressure gradient force and advection scheme used for forecasting with steep and small scale topography. Contributions in Atmospheric Physics, 50, 186-199.

[3] Janjic, Z. I., 1979 Forward-backward scheme modified to prevent two grid-interval noise and its application in sigma coordinate models. Contributions in Atmospheric Physics, 52, 69-84.

[4] Janjic, Z. I., 1984 Non-linear advection schemes and energy cascade on semi-staggered grids. Monthly Weather Review, 112, 1234-1245.

[5] Janjic, Z. I., 1990 The step-mountain coordinate: Physical package. Monthly Weather Review, 118, 1429-1443.

[6] Janjic, Z. I., 1994 The Step-Mountain Eta Coordinate Model: Further Developments of the Convection, Viscous Sublayer, and Turbulence Closure Schemes. Monthly Weather Review, 122, 927-945.

[7] Janjic, Z. I., 1996 The surface layer parameterization in the NCEP Eta Model. World Meteorological Organisation, Geneva, Switzerland.

[8] Mesinger et al., 1988 The Step-Mountain Coordinate: Model Description and Performance for Cases of Alpine Lee Cyclogenesis and for a Case of an Appalachian Redevelopment. Monthly Weather Review, 116, 1493-1518.

[9] Black, T. L., 1994 The New NMC Mesoscale Eta Model: Description and Forecast Examples. Weather and Forecasting - NMC Notes, 9, 265-278.

[10] Mesinger, E., 1997 Dynamics of limited area models: Formulation and numerical methods. Journal of Atmospheric Physics, 63, 3-14.

[11] Shao, Y., M. R. Raupach and P. A. Findlater, 1993 Effect of saltation bombardment on the entrainment of dust by wind. Journal of Geophysical Research, 98, D7, 12719-12726.

[12] Fecan, F., B. Marticorena and G. Bergametti, 1999 Parameterization of the increase of the aeolian erosion threshold wind friction velocity due to soil moisture for arid and semi-arid areas. Annales Geophysicae, 17, 149-157.

[13] Giorgi, F., A particle dry-deposition parameterization scheme for use in tracer transport models. Journal of Geophysical Research, 91, 9794-9804, 1986.

[14] Pérez, C., S. Nickovic, G. Pejanovic, J. M. Baldasano, and E. Özsoy, 2006 Interactive dustradiation modeling: A step to improve weather forecasts. Journal of Geophysical Research, doi:10.1029/2005JD006717.

[15] Zender, C. S., H. Bian, and D. Newman 2003 Mineral Dust Entrainment and Deposition (DEAD) model: Description and 1990s dust climatology. Journal of Geophysical Research, 108, D14, doi:10.1029/2002JD002775.

[16] Shettle, E. P., 1984 Optical and radiative properties of a desert aerosol model. Proceedings of the Symposium on Radiation in the Atmosphere.

[17] Schulz, M., Y. J. Balkanski, W. Guelle and F. Dulac, 1998 Role of aerosol size distribution and source location in a three-dimensional simulation of a Saharan dust episode tested against satellite-derived optical thickness. Journal of Geophysical Research, 103, D9, 10579-10592.

[18] Pérez, C., S. Nickovic, J. M. Baldasano, M. Sicard, F. Rocadenbosch and V. E. Cachorro. 2006 A long Saharan dust event over the Western Mediterranean: lidar, sun photometer observations and regional dust modeling. Journal of Geophysical Research, 111, D15214, doi:10.1029/2005JD006579.

[19] Balis D., V. Amiridis, S. Kazadzis, A. Papayannis, G. Tsaknakis, S. Tzortzakis, N. Kalivitis, M. Vrekoussis, M. Kanakidou, N. Mihalopoulos, G. Chourdarkis, S. Nickovic, C. Pérez, J.M. Baldasano and M. Drakakis 2006 Optical characteristics of desert dust over the East Mediterranean during summer: a case study. Annales Geophysicae, 24. 
[20] Jiménez-Guerrero, P., C. Pérez, O. Jorba and J. M. Baldasano, 2008 Contribution of Saharan dust in an integrated air quality system and its on-line assessment. Geophysical Research Letters, 35(3).

[21] Haustein, K., Pérez, C., Baldasano, J.M. et al., 2009 Regional dust model performance during SAMUM 2006. Geophysical Research Letters (in press).

[22] Todd, M. C., D. B. Karam, C. Cavazos, C. Bouet, B. Heinold, J.M. Baldasano, G. Cautenet, I. Koren, C. Perez, F. Solmon, I. Tegen, P. Tulet, R. Washington, and A. Zakey 2008 Quantifying uncertainty in estimates of mineral dust flux: an inter-comparison of model performance over the Bodélé Depression, Northern Chad. J. Geophys. Res., doi:10.1029/2008JD010476, in press.

[23] Baldasano, J.M., Jiménez-Guerrero, P., Jorba, O., Pérez, C., López, E., Güereca, P., Martín, F., García-Vivanco, M., Palomino, I., Querol, X., Pandolfi, M., Sanz, M.J., Diéguez, J.J., 2008 CALIOPE: an operational air quality forecasting system for the Iberian Peninsula, Balearic Islands and Canary Islands. Current status and future plans. Advances in Science and Research 2, 89-98.

[24] Baldasano J.M., L. P. Güereca, E. López, S. Gassó, P. Jimenez-Guerrero 2008 Development of a high resolution $(1 \mathrm{~km} \times 1 \mathrm{~km}, 1 \mathrm{~h})$ emission model for Spain: the High-Elective Resolution Modelling Emission System (HERMES). Atmospheric Environment, 42 7215-7233.

[25] Kishcha et al., 2003 Atmospheric response to Saharan dust deduced from ECMWF reanalysis (ERA) temperature increments. Tellus, 55, Serie B, 901-913.

[26] Haywood et al., 2005 Can desert dust explain the outgoing longwave radiation anomaly over the Sahara during July 2003? Journal of Geophysical Research, 110, doi:10.1029/2004JD005232.

[27] Prospero, J. M., 1999 Long-term measurements of the transport of African mineral dust to the southeastern United States: Implications for regional air quality. Journal of Geophysical Research, 104, D13, 15917-15927.

[28] Moulin et al., 1997 Control of atmospheric export of dust from North Africa by the North Atlantic oscillation. Nature, 387 (6634), 691-694.

[29] Ginoux, P., J. M. Prospero, O. Torres and M. Chin, 2004 Long-term simulation of global dust distribution with the GOCART model: correlation with North Atlantic Oscillation. Environmental Modelling \& Software, 19, 113-128.

[30] Pérez C., P. Jiménez, O. Jorba, J. M. Baldasano, E. Cuevas, S. Nickovic, X. Querol 2007 Longterm simulations (1958-2006) of Saharan dust over the Mediterranean and the Eastern North Atlantic with the DREAM regional dust model. IUGG 2007 Perugia, Session: MS004 Mineral Dust Cycle and its Impact on Clouds and Radiation (ICCP), Perugia (Italia), 2-13, July.

[31] Pérez, C., Haustein, K., Janjic, Z., Jorba, O., Baldasano, J.M., Black, T., Nickovic, S. 2008 An online mineral dust model within the global/regional NMMB: current progress and plans. AGU Fall Meeting. San Francisco, 15-19, December 2008. 